\title{
Country Studies of Interchange Fees: Commentary
}

\author{
ROBIN PRAGER * \\ Board of Governors of the Federal Reserve System
}

\begin{abstract}
The following is a transcription of my discussion of the three papers (published in this issue) that were presented in the "Panel of Country Studies" session of the Antitrust Activity in Card-Based Payment Systems: Causes and Consequences conference.
\end{abstract}

\section{Commentary}

Good afternoon. I'd like to begin by thanking Jamie for inviting me to participate in the conference. He has put together a truly outstanding program, and I very much appreciate the opportunity to be a part of it. Before I discuss the papers, I am required to tell you that the views I express are my own, and do not necessarily represent the views of the Board of Governors of the Federal Reserve System or anybody else who works there.

As you've heard several times already today, over the past few years research involving the theory of two-sided markets and, in particular, the role of interchange fees in those markets, has been somewhat of a growth industry. The topic has attracted the attention of some of the most respected names in industrial organization theory, and these folks have generated an impressive volume of research over a very short period of time.

Empirical research on this topic, however, as you've also heard today, has been far less abundant. This is not because empirical economists are less interested in the topic than are theorists. Rather, it is due to the fact that in order to do empirical work we need data, and there is a serious shortage of data in this area. The three papers that you just heard presented in this session take an important step towards ameliorating the research imbalance by providing some very interesting empirical evidence regarding the development of payment networks in a number of different countries. At the same time, they serve to remind us of the limitations imposed by the data.

The papers in this session are not your standard empirical analyses. Rather, the authors of these papers have utilized two different and, I believe, nicely complementary approaches that are well suited to conducting an empirical investigation in a setting where data are severely limited.

\footnotetext{
* Mailing address: Financial Structure Section, Division of Research and Statistics, Board of Governors of the Federal Reserve System, Washington, DC 20551, 202-452-3643, E-mail: robin.prager@frb.gov
} 
I am going to talk about these papers in the reverse order from that in which they were presented, starting with Stu and Julian's paper. Stu and Julian have put together what is essentially a standardized set of information about the payments networks in a number of different countries, and have organized it in a way that facilitates interesting and informative cross-country comparisons. Given the heterogeneity of the information that they've gathered, I think they have done an impressive job of compiling comparable facts and figures for the various countries that they examine. Their tables enable us to see, at a glance, some of the key characteristics of the payments networks in each country, and serve to highlight the similarities and differences across these ten observations. I'd like to briefly mention a few of the things that I learned from reading their paper.

First of all, usage of credit and debit cards varies considerably across countries. In Denmark and the Netherlands, credit cards account for only about $1 \%$ of non-cash transactions, while in the US, Canada, and Australia they account for more than $20 \%$. Signature-based debit is virtually nonexistent in some countries, such as Canada, Denmark and the Netherlands, while accounting for a very substantial share of non-cash transactions in the US and Spain. Likewise, PIN-based debit plays a very important role in some countries and doesn't really even exist in Mexico or Spain.

A second interesting fact is that, although, in most countries, the interchange fees for Visa and MasterCard are set collectively by the members of the network, this is not universally true. We heard about Mexico, where the association of Mexican banks sets the rates and the rates are the same for both Visa and MasterCard. In Sweden, the rates are negotiated bilaterally.

Thirdly, in most countries where PIN-based debit service exists, only one or two networks provide the service, but in the US there are more than a dozen PIN debit networks.

Fourth, Stu and Julian's tables show that, consistent with the predictions of the theoretical models, there appears to be an inverse relationship between movements in credit card interchange fees and cardholder fees. In Australia and Spain, for example, over the last few years, interchange fees have been declining and annual cardholder fees have been on the rise; in the US, on the other hand, interchange fees have been rising and annual cardholder fees have been declining.

Finally, the roles played by the antitrust authorities and central banks in influencing operating rules and pricing in payment card networks have varied considerably across countries.

The other two papers in this session each present a detailed case study of a single country's experience. These papers clearly illustrate the fact that, in each country, a wide range of factors have come into play in influencing the development of payments networks. The rich details provided in each paper reveal important aspects of that country's history that help explain some of the observed characteristics of their current payments networks, and which would, frankly, be hidden from view in any standard cross-sectional analysis.

David and Yossi's paper tells a fascinating tale of the Israeli Antitrust Authority's largely unsuccessful efforts to introduce competition into the Israeli credit card industry. It is clear that history and the structure of the Israeli banking market have played important roles in shaping the credit card industry in that country. It is also clear that, for a number of reasons, it will be very difficult for Israel to move away from the current industry structure.

The greatest impediments to changing the structure of the Israeli credit card industry are (i) the extremely high level of concentration in the Israeli banking industry; (ii) the fact that credit card issuance is effectively tied to deposit accounts in Israel; (iii) the fact that virtually all adults in Israel already hold credit cards; (iv) the high level of credit card usage in Israel, which the 
authors interestingly speculate may stem from a reluctance to hold cash that has its roots in the hyperinflation of the early 1980s; and (v) an apparent reluctance of the credit card companies to intrude on each other's turf by issuing and acquiring cards on each other's networks.

Although the Israeli Antitrust Authority and the Court for Trade Restrictions have tried to force the networks and the credit card companies to design a well-documented and justifiable methodology for determining interchange fees, so far those efforts have failed. Likewise, efforts to bring about meaningful competition in credit card markets have not had much success.

Finally, I'd like to talk about Jose's paper. This paper provides a revealing look at the credit card and debit card markets in Mexico. His data show that usage and acceptance of credit and debit cards in Mexico is low compared with other countries. Jose points to a number of factors that may underlie the slow development of payment card networks in Mexico, including the interchange fee structure, which appears to discriminate against small merchants and discourage their participation in accepting cards. While this no doubt has played a role in limiting card acceptance at the point of sale, I suspect that a more fundamental problem may be the fact that a large proportion of the Mexican population is "unbanked". Given the key role that banks play in issuing credit cards, and the fact that debit cards are necessarily linked to deposit accounts, it would seem difficult to increase card holding and usage without first convincing households to establish banking relationships. So, despite the fact that the Mexican Treasury is attempting to accelerate the development of payments networks by subsidizing installations of POS terminals, it is not clear how much impact they can have, as long as people are unwilling to hold deposit accounts at banks.

Together, these three studies bring to light the similarities and differences in payment card networks across a number of countries. Perhaps the most striking finding to emerge from these studies is the degree to which payment card usage, industry structure and organization, and the nature and extent of regulatory intervention vary across countries. Clearly, the evolution of payments networks in each country has been influenced by the prevailing economic, political and social conditions in that country. Unfortunately, this makes it very difficult for us to answer even such a straightforward question as "What factors determine the level of interchange fees that we observe in a particular country?" not to mention the far more challenging question of "How should interchange fees be set in order to maximize social welfare?" It seems that we still have quite a bit of work to do.

So, where do we go from here? I believe that the types of papers that were presented in this session, which really delve into the details of individual country histories, are very valuable. I would encourage researchers to follow the example set by our presenters this afternoon and to produce detailed case studies of the evolution of payments networks for a larger set of countries. I would also suggest that the scope of the studies should be expanded to include explicit consideration of the structure of the banking industry and the nature of banking relationships in the country. Why do people in Mexico have an apparent reluctance to open deposit accounts, while in Israel, both deposit accounts and card usage are much more widespread?

Researchers should also examine the characteristics of the credit markets in these countries, including the role of credit rating agencies in making information about individuals' credit histories more readily available. In the US, credit rating agencies have played a very important role in making the credit card market more competitive and in making credit available to a wider subset of the population. What role have these entities played in other countries?

Anther important factor to consider is the nature of consumer preferences regarding the usage of various payment methods. Do individuals prefer to use a credit card, debit card, cash, or check 
for a particular type of transaction? How does the choice of payment method vary with individual characteristics and with the location or value of the transaction? I believe the best way to gather this type of information is probably through consumer surveys.

Gathering and analyzing all of these types of information for a large number of countries will not yield an answer to the question of "What is the socially optimal interchange fee?" However, it will enable us to put together a base of knowledge that will significantly enhance our understanding of payment card markets and thereby facilitate more well-informed policy decisions. 